\title{
DOWNLOAD INTENTION IN THE MOBILE APPLICATION MARKETPLACE
}

\author{
Chien-Yun Yuan, Chihlee University of Technology, cy_yuan@mail.chihlee.edu.tw \\ Wen-Hai Chih, National Dong Hwa University, whchih@mail.ndhu.edu.tw \\ Chia-Yi Huang, Distell, vicky171989@hotmail.com
}

\begin{abstract}
This research explores how to convince consumers to purchase and download application software to achieve commercial goals. This research proposes a model to understand the development process of download intention for mobile application users by investigating the relationships among interactivity, social presence, and download intention. This study also tests the mediation effects of social presence and makes conclusions based on the statistical analysis results. In addition, this study provides managerial implications for social community managers.
\end{abstract}

Keywords: Mobile Application Marketplace, Interactivity, Social Presence, Download Intention

\section{INTRODUCTION}

A mobile application (MA) is a kind of software that provides digital product consumption and service. An MA is installed inside a mobile device and displayed on websites. Research and develop people announce and sell MAs in the mobile application marketplaces (MAMs). Consumers browse relevant information and comment about MAs through MAMs uploading and downloading these applications according to their demands (Amberg, Thiessen, Lang, \& Belkius, 2010). MAMs are platforms on which consumers can exchange information and sell/buy products, where enterprises display their products, and where consumers select and purchase merchandise. It is how mobile device users download MAs to satisfy their personal needs and enterprises earn profit (Song, Kim, Jones, Baker, \& Chin, 2014).

MAMs provide special service for mobile device users through Android, iPhone, Windows Phone, and BlackBerry and enable users to browse and upload/download MAs (Cuadrado \& Dueñas, 2012). Successful and famous MAMs include Apple's App Store, Android's Google Play, and BlackBerry's App World (Song et al., 2014). Suppliers who want to offer their commodities on MAMs must pay a slotting fee based on different types of MAMs. The slotting fee of Google Play is cheaper than that of the App Store and of the App World. In Taiwan, the percentage of Android users is higher than iPhone, Windows Phone, and BlackBerry users. Therefore, this study investigates Google Play as the MAM research target in Taiwan.

\section{Google Play Store}

Google announced the Android operating system in 2007. Android is a mobile operating system based on Linux, a system programming language, and designed for smart phones and tablet computers. Google changed the name of the Android market to the Google Play Store on the Android platform in 2012. The application media platform of Google music, e-books, and video is known as Play Music, Play Books, and Play Movies, respectively (Wimberly, 2012). Android users can browse all kinds of commodities, download various MAs, review for MAs, and provide opinions in the Google Play Store.

Since 2012, the Android market share has been over 70\% in the global mobile device market (IDC, 2015). During that time, Android has developed over 48 billion MAs. The system programming language of Android, Linux, is easy to understand and learn compared to the Apple iOS (Ntantogian, Apostolopoulos, Marinakis, \& Xenakis, 2014). An enterprise that is trying to sell MAs must pay Google Play for a slotting fee as well as a fee to the Apple Store. However, the slotting fee of Google Play is cheaper than the App Store. For most small and medium enterprises (SMEs) using Android for all MAMs seems to be a good choice. 


\section{Interactivity}

Liu and Shrum (2002) were the first scholars to study interactivity in the marketing area. They defined interactivity as two or two more users exchanging messages in communication media with synchronicity, influence, and responsiveness. Interactivity can be interpreted as communication, searching for information, or performing an MA transaction between users and enterprise through the Internet (Yoo, Lee, \& Park, 2010; Zeithaml, Parasuraman, \& Malhotra, 2002). A system possesses interactivity characteristics with high levels of autonomy and adjustability if users can chose the functions they want, and the platform can provide synchronic feedback to allow users to proceed with two-way communication in information research (Jiang \& Benbasat, 2007; Teo, Oh, Liu, \& Wei, 2003).

This study proposes that interactivity is composed of two-way communication, synchronicity, and responsiveness based on previous research and the specific context. It also investigates the two-way communication, synchronicity, and responsiveness of interactivity for MAs users in MAMs. Two-way communication provides a service channel to allow users and enterprises to deliver messages and communicate with each other on MAMs (Liu \& Shrum, 2002; van Noort, Voorveld, \& van Reijmersdal, 2012). Synchronicity is the speed of exchange information and response to achieve effective communication between users and enterprises on MAMs. Enterprises must be able to synchronously and respond to users' needs in a timely way to achieve synchronicity in the exchange of an electronic commodity (Liu \& Shrum, 2002). Responsiveness is the basis for information exchange to raise the reliability, communication efficiency, and accuracy of MAMs. Therefore, responsiveness is one of the strategic factors that enable MAMs to maintain relationships with users (Avidar, 2013; Johnson, Bruner II, \& Kumar, 2006).

\section{Social Presence}

Internet users can build a relationship between users to understand other psychological perceptions through a connection in the social network. Social network sites allow people to build different levels of sensation, awareness, or responses to others (Xu, Ryan, Prybutok, \& Wen, 2012). Social presence is the perception and reaction of users during the mobile device junction in the electronic media research and it is a subjective concept of intimacy and immediacy of electronic media through mobile device (Tung \& Deng, 2007).

Researchers propose intimacy, co-presence, and immediacy as a social presence (Biocca, Harms, \& Burgoon, 2003). Therefore, this study classifies social presence into intimacy, co-presence, and immediacy to investigate the decision process of users browsing MAMs. Intimacy is defined as the existence of an affection relationship, connectivity, and attachment in an interpersonal relationship (Sternberg, 1986). Intimacy is assumed as the connection of personal subjective awareness, self-expression, and interaction in the relationship between an individual and others (Greene, Derlega, \& Mathews, 2006; Park, Jin, \& Annie Jin, 2011). Co-presence is an individual's perception of coexisting with others in the same space to share a virtual community platform or space in e-commerce (Zhao, 2003). Immediacy in an information system is the psychological distance between users and the active behavior of users to face love or intimacy. In other words, immediacy is the immediate and active reaction of users in the virtual environment. This kind of immediate response or reaction can be transmitted verbally or non-verbally (Tu \& McIsaac, 2002).

\section{Download Intention}

Ajzen and Fishbein (1969) proposed behavior intention in their theory of reasoned action (TRA). It is used to predict people's societal behavior intentions and can be defined as their willingness to adopt for a specific behavior. Therefore, TRA intention can be used to measure an individual's willingness to commit a specific behavior (Ajzen \& Fishbein, 1969). Download intention means that an individual has a strong willingness to download specific software in the future. Because of the massive number of MAs, most users are not familiar with all products. The strength of download willingness is different according to the amount of information provided by MAMs, the frequency use of MAMs, and MAs assessment level, which helps users decide the product value through the introduction of MAMs products (Hsu \& Lin, 2015). 


\section{RESEARCH METHODOLOGY}

By constructing an SEM model, this study investigates the relationships among interactivity, social presence, and download intention. This study proposes the following research hypotheses.

$\mathrm{H}_{1}$ : Interactivity has significant and positive effects on (a) intimacy, (b) co-presence, and (c) immediacy.

$\mathrm{H}_{2}$ : (a) Intimacy, (b) co-presence, and (c) immediacy have significant and positive effects on download intention.

$\mathrm{H}_{3}$ : Interactivity has a significant and positive effect on download intention.

This study aims to explore users' behaviors on MAMs. This study adopts measurement items from previous research to assure the validity of the questionnaire. Measurement items are adopted from Ou, Pavlou \& Davison (2014) for two-way communication, synchronicity, co-presence, and immediacy; Zhao \& Lu (2012) for responsiveness; Lee \& Kwon (2011) for intimacy; Wang, Chen, Yang \& Farn (2009) for download intention, using a 7-point Likert-scale anchored from (1) strongly disagree to (7) strongly agree. There are 22 measurement items on the questionnaire.

\section{RESULTS}

This study collects a total of 450 samples. There are 375 valid survey samples, yielding a response rate of $83.33 \%$. The demographics of the sample population are shown in Table 1. The sample indicates more female (54.67\%) than male $(45.33 \%)$ participants. According to statistical information from the Taiwan Network Information Center (TWNIC) (2015), the result of the Chi-square goodness-of-fit test shows the $\chi^{2}$-value is 0.485 ( $p$ value $=0.826>0.050)$. Thus, no significance difference exists between the sample structure and the population structure of Taiwanese social network users' gender ratio provided by the TWNIC in this study.

Table 1. Demographics

\begin{tabular}{lcccc}
\hline Item & Variable & Frequency & Percent (\%) & $\begin{array}{c}\text { Accumulated } \\
\text { Percentage (\%) }\end{array}$ \\
\hline Gender & Male & 170 & 45.33 & 45.33 \\
& Female & 205 & 54.67 & 100.00 \\
\hline Age & $<19$ & 104 & 27.73 & 27.73 \\
& $20-24$ & 186 & 49.60 & 77.33 \\
& $25-29$ & 25 & 6.67 & 84.00 \\
& $30-34$ & 28 & 7.47 & 91.47 \\
& $35-39$ & 17 & 4.53 & 96.00 \\
& $>40$ & 15 & 4.00 & 100.00 \\
\hline Educational & High School & 17 & 4.53 & 4.53 \\
& College & 322 & 85.87 & 85.87 \\
& Graduate & 36 & 9.60 & 9.60 \\
\hline Cost of APP Every Month & $<\$ 50$ & 304 & 81.07 & 81.07 \\
& $\$ 51-100$ & 30 & 8.00 & 8.00 \\
& $\$ 101-200$ & 18 & 4.80 & 4.80 \\
& $\$ 201-300$ & 13 & 3.47 & 3.47 \\
& $\$ 301-500$ & 10 & 2.67 & 2.67 \\
\hline Use APP Every Day & $<10$ minute & 58 & 15.47 & 15.47 \\
& $11-20$ minute & 40 & 10.67 & 10.67 \\
& $21-30$ minute & 48 & 12.80 & 12.80 \\
& $31-60$ minute & 41 & 10.93 & 10.93 \\
& $1-2$ hours & 56 & 14.93 & 14.93 \\
& $2-3$ hours & 39 & 10.40 & 10.40 \\
& $>3$ hours & 93 & 24.80 & 24.80 \\
\hline
\end{tabular}


As essential prerequisites for achieving valid results, this study assesses the reliability, convergent validity, and discriminant validity of the measurement model. Items reliability is assessed by applying the factor loading and squared multiple correlations (SMC), and the construct reliability is assessed by applying Cronbach $\alpha$. This study conducts the convergent validity in terms of the average variance extracted (AVE) and composite reliability (CR) for the latent variables. As shown in Table 1, all of the measurement model indexes are above the criteria. Thus, the validity is confirmed (Bagozzi \& Yi, 1988; Bentler \& Wu, 1993; Hair Jr., Black, Babin, \& Anderson, 2010; Nunnally, 1978).

Table 2. Measurement Constructs and Confirmatory Factor Analysis (Measurement Model)

\begin{tabular}{|c|c|c|c|c|c|}
\hline Scale/Item & $\begin{array}{l}\text { Factor } \\
\text { Loading }\end{array}$ & SMC & CR & AVE & Conbach's $\alpha$ \\
\hline Interactivity & & & 0.653 & 0.538 & 0.752 \\
\hline TWC & 0.696 & 0.484 & & & \\
\hline SYN & 0.858 & 0.736 & & & \\
\hline RES & 0.627 & 0.393 & & & \\
\hline Two-way Communication & & & 0.761 & 0.696 & 0.820 \\
\hline TWC1 & 0.823 & 0.677 & & & \\
\hline TWC2 & 0.845 & 0.714 & & & \\
\hline Synchronicity & & & 0.603 & 0.571 & 0.732 \\
\hline SYN1 & 0.787 & 0.619 & & & \\
\hline SYN2 & 0.723 & 0.523 & & & \\
\hline Responsiveness & & & 0.654 & 0.539 & 0.776 \\
\hline RES1 & 0.667 & 0.445 & & & \\
\hline RES2 & 0.695 & 0.483 & & & \\
\hline RES3 & 0.830 & 0.689 & & & \\
\hline Intimacy & & & 0.721 & 0.506 & 0.833 \\
\hline INT1 & 0.759 & 0.576 & & & \\
\hline INT2 & 0.738 & 0.545 & & & \\
\hline INT3 & 0.557 & 0.310 & & & \\
\hline INT4 & 0.770 & 0.593 & & & \\
\hline INT5 & 0.710 & 0.504 & & & \\
\hline Co-presence & & & 0.728 & 0.549 & 0.827 \\
\hline $\mathrm{CP} 1$ & 0.701 & 0.491 & & & \\
\hline $\mathrm{CP} 2$ & 0.725 & 0.526 & & & \\
\hline $\mathrm{CP} 3$ & 0.767 & 0.588 & & & \\
\hline CP4 & 0.769 & 0.591 & & & \\
\hline Immediacy & & & 0.618 & 0.513 & 0.748 \\
\hline IMD1 & 0.692 & 0.479 & & & \\
\hline IMD2 & 0.779 & 0.607 & & & \\
\hline IMD3 & 0.673 & 0.453 & & & \\
\hline Download Intention & & & 0.652 & 0.537 & 0.764 \\
\hline DI1 & 0.748 & 0.560 & & & \\
\hline DI2 & 0.745 & 0.555 & & & \\
\hline 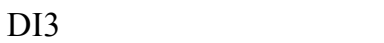 & 0.705 & 0.497 & & & \\
\hline
\end{tabular}

Moreover, Table 2 indicates that correlation between any two variables is lower than 0.8 , thus showing discriminant validity (Fornell \& Larcker, 1981; Gaski \& Nevin, 1985). 
Table 3. Correlation Matrix

\begin{tabular}{lccccccccc}
\hline \multicolumn{1}{c}{ Variable } & Mean & SD & $\mathbf{1}$ & $\mathbf{2}$ & $\mathbf{3}$ & $\mathbf{4}$ & $\mathbf{5}$ & $\mathbf{6}$ & $\mathbf{7}$ \\
\hline 1. Two-way & 5.51 & 0.92 & 1 & & & & & & \\
Communication & 5.92 & & & & & & & \\
2. Synchronicity & 5.83 & 0.79 & $0.425^{* * *}$ & 1 & & & & & \\
3. Responsiveness & 5.24 & 0.89 & $0.448^{* * *}$ & $0.277^{* * *}$ & 1 & & & & \\
4. Intimacy & 5.41 & 0.72 & $0.425^{* * *}$ & $0.378^{* * *}$ & $0.515^{* * *}$ & 1 & & & \\
5. Co-presence & 5.54 & 0.74 & $0.498^{* * *}$ & $0.520^{* * *}$ & $0.472^{* * *}$ & $0.623^{* * *}$ & 1 & & \\
6. Immediacy & 5.94 & 0.71 & $0.316^{* * *}$ & $0.590^{* * *}$ & $0.241^{* * * *}$ & $0.383^{* * *}$ & $0.419^{* * *}$ & 1 & \\
7. Download Intention & 5.61 & 0.79 & $0.387^{* * *}$ & $0.436^{* * * *}$ & $0.462^{* * * *}$ & $0.641^{* * * *}$ & $0.614^{* * *}$ & $0.391^{* * *}$ & 1 \\
\hline
\end{tabular}

Note: $* * *: p<0.001$

This study examines structural equation modeling and verifies the indices of model fit as suggested by Hair Jr. et al. (2010). As shown in Figure 1, although all model fit indices are higher than the suggested criteria, not all of the hypotheses are supported only $\mathrm{H}_{1 \mathrm{a}}, \mathrm{H}_{1 \mathrm{~b}}, \mathrm{H}_{1 \mathrm{c}}$, and $\mathrm{H}_{2 \mathrm{c}}$ are supported while $\mathrm{H}_{2 \mathrm{a}}, \mathrm{H}_{2 \mathrm{~b}}$, and $\mathrm{H}_{3}$ are not supported. This result infers that interactivity affects download intention through mediation variables (social presence).

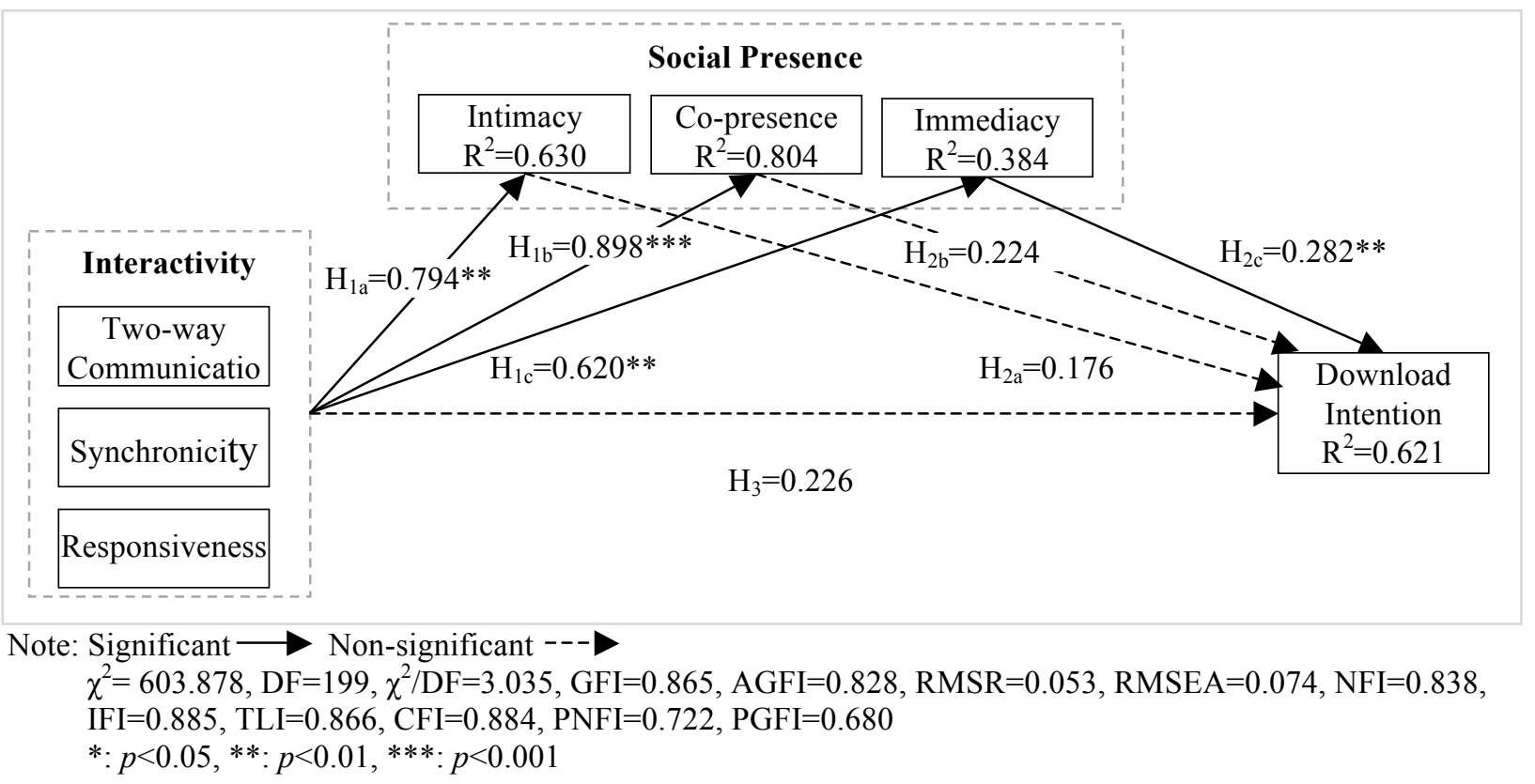

Figure 1. Structural Model Results with Social Presence

To verify the mediation effect of social presence, this research conducts the Sobel test and Bootstrapping analysis. Table 4 shows the three steps used to test the mediation effect (Baron \& Kenny, 1986; Komiak \& Benbasat, 2006). The $\mathrm{Z}$ values of the Sobel test indicate the significance of the mediation effects (Wood, Goodman, Beckmann, \& Cook, 2008). Table 5 indicates that the $95 \%$ confidence intervals of percentile method and bias-corrected of the Bootstrapping analysis do not contain zero. These results indicate that all of the mediation effects are supported. 
Table 4. The Mediation Effects of Social Presence

\begin{tabular}{ccccccccc}
\hline \multirow{2}{*}{ IV } & \multirow{2}{*}{$\mathbf{M}$} & \multirow{2}{*}{$\mathbf{D V}$} & \multirow{2}{*}{$\mathbf{I V} \rightarrow \mathbf{D V}$} & $\mathbf{I V} \rightarrow \mathbf{M}$ & \multicolumn{2}{c}{$\mathbf{I V + M} \rightarrow \mathbf{D V}$} & \multicolumn{2}{c}{ Sobel Test } \\
\cline { 6 - 9 } & & & & & $\mathbf{I V}$ & $\mathbf{M}$ & Statistic (Z) & $\boldsymbol{p}$-value \\
\hline IT & INT & DI & $0.455^{* * *}$ & $0.619^{* * *}$ & $0.290^{* * *}$ & $0.266^{* * *}$ & 5.33 & 0.000 \\
IT & CP & DI & $0.455^{* * *}$ & $0.713^{* * *}$ & $0.246^{* * *}$ & $0.293^{* * *}$ & 6.10 & 0.000 \\
IT & IMD & DI & $0.455^{* * *}$ & $0.516^{* * *}$ & $0.331^{* * *}$ & $0.241^{* * *}$ & 4.63 & 0.000 \\
\hline
\end{tabular}

Note: IV: Independent Variable; M: Mediating Variable; DV: Dependent Variable;

IT: Interactivity; INT: Intimacy; CP: Co-presence; IMD: Immediacy; DI: Download Intention

Table 5. The Bootstrapping Analysis for the Mediating Effects of Social Presence

\begin{tabular}{cccccccccc}
\hline \multirow{2}{*}{ IV } & \multirow{2}{*}{ M } & \multirow{2}{*}{ DV } & $\begin{array}{c}\text { Indirect } \\
\text { Effect }\end{array}$ & Mean & S.E. & \multicolumn{3}{c}{ Bootstrapping 95\% CI } \\
\cline { 6 - 9 } & & & & Percentile Method & Bias-corrected \\
\hline IT & INT & DI & 0.165 & 0.165 & 0.033 & 0.105 & 0.232 & 0.102 & 0.233 \\
IT & CP & DI & 0.209 & 0.210 & 0.039 & 0.137 & 0.288 & 0.137 & 0.291 \\
IT & IMD & DI & 0.124 & 0.124 & 0.025 & 0.077 & 0.177 & 0.076 & 0.178 \\
\hline
\end{tabular}

Note: IV: Independent Variable; M: Mediating Variable; DV: Dependent Variable;

IT: Interactivity; INT: Intimacy; CP: Co-presence; IMD: Immediacy; DI: Download Intention

\section{SUMMARY}

Eighty-one percent of the Taiwanese population uses smart phone, a higher percentage than in Japan and South Korea (Chen, 2013). Based on a survey by Foreseeing Innovative New Digiservices (FIND) with Mobile First, there are over 16 million people over 12 years of age using a smart phone or tablet computer in Taiwan. Mobile device users increased by 1.7 million in the first six months of 2015. One out of every two people possesses a smart mobile device such as a smart phone or a tablet computer (Institute for Information Industry, 2015). In the transformation from standard mobile phone to smart phone, the change in communication has altered consumers' lives through activities such as streaming media of globalization, smart home, electronic wallet (e-wallet), personal information management, medical insurance, and home security (Ericsson, 2015). People highly rely on the habit of using smart phones in their daily lives and work (Wang, Wang, Gaskin, \& Wang, 2015).

Free product can remove psychological transaction cost and increase decision speed. Therefore, through intensive competition, MAMs provide various free MA trials and users have many choices from various free MAs for the similar type (Hsu \& Lin, 2015; Wimberly, 2012). Due to the uncertainty of transactional environment in the Internet, consumers can evaluate and comment in regard to rely on useful information on the Internet such as MAMs to understand products and make their decisions (Hsu \& Lin, 2015). As customers' first priority is to download free trial MAs in the current network environment, enterprise should provide such MAs to help advance subsequent purchasing behavior.

\section{REFERENCES}

Ajzen, I., \& Fishbein, M. (1969). The prediction of behavioral intentions in a choice situation. Journal of Experimental Social Psychology, 5(4), 400-416.

Amberg, M., Thiessen, I., Lang, M., \& Belkius, B. (2010). Mobile application marketplaces-An investigation from customers' perspective. Die Multikonferenz Wirtschaftsinformatik, pp. 541-554.

Avidar, R. (2013). The responsiveness pyramid: Embedding responsiveness and interactivity into public relations theory. Public Relations Review, 39(5), 440-450.

Bagozzi, R. P., \& Yi, Y. (1988). On the evaluation of Structural Equation Models. Journal of the Academy of 
Marketing Science, 16(1), 74-94.

Baron, R. M., \& Kenny, D. A. (1986). The moderator-mediator variable distinction in social psychological research: Conceptual, strategic, and statistical considerations. Journal of Personality and Social Psychology, 51(6), 1173-1182.

Bentler, P. M., \& Wu, E. J. C. (1993). EQS/Windows user guide. Los Angeles, CA: BMDP Statistical Software.

Biocca, F., Harms, C., \& Burgoon, J. (2003). Toward a more robust theory and measure of social presence: Review and suggested criteria. Presence, 12(5), 456-480.

Chen, C. J. (2013). Google: Taiwanese mobile phone dependence is $81 \%$, the top of Asia. Available: http://www.moneydj.com/KMDJ/News/NewsViewer.aspx?a=18e6e71e-5ad9-496a-93008e8b8c5a29f0\#ixzz2cNht8CbC.

Cuadrado, F., \& Dueñas, J. C. (2012). Mobile application stores: Success factors, existing approaches, and future developments. IEEE Communications Magazine, 50(11), 160-167.

Ericsson (2015). 2015 top ten consumer trends. Available: http://www.ericsson.com/res/site_TW.

Eroglu, S. A., Machleit, K. A., \& Davis, L. M. (2003). Empirical testing of a model of online store atmospherics and shopper responses. Psychology \& Marketing, 20(2), 139-150.

Fornell, C., \& Larcker, D. F. (1981). Evaluating Structural Equation Models with unobservable variables and measurement error. Journal of Marketing Research, 18(1), 39-50.

Gaski, J. F., \& Nevin, J. R. (1985). The differential effects of exercised and unexercised power sources in a marketing channel. Journal of Marketing Research, 22(2), 130-142.

Greene, K., Derlega, V. J., \& Mathews, A. (2006). Self-disclosure in personal relationships. In Vangelisti, A. L. (Ed.). The Cambridge handbook of personal relationships, 409-427, Cambridge, UK: Cambridge University Press.

Hair, J. F. Jr., Black, W. C., Babin, B. J., \& Anderson, R. E. (2010). Multivariate data analysis (7 ${ }^{\text {th }}$ Ed.). Upper Saddle River, NJ: Prentice-Hall.

Hsu, C. L., \& Lin, J. C. C. (2015). What drives purchase intention for paid mobile apps? An expectation confirmation model with perceived value. Electronic Commerce Research and Applications, 14(1), 46-57.

Institute for Information Industry (2014). FIND(2014)/Services Experience Design Innovation Research and Promote Project (2/4). Available: http://www.find.org.tw/market_info.aspx?n_ID=7201.

Institute for Information Industry (2015). FIND(2015)/Services Experience Design Innovation Research and Promote Project (3/4). Available: http://www.find.org.tw/market_info.aspx?n_ID=8482.

International Data Corporation (2015). Global Smartphone growth expected to slow to $11.3 \%$ in 2015 as market penetration increases in top markets. Available: http://www.idc.com/getdoc.jsp?containerId=prUS25641615. 
Jiang, Z., \& Benbasat, I. (2007). Research note-investigating the influence of the functional mechanisms of online product presentations. Information Systems Research, 18(4), 454-470.

Johnson, G. J., Bruner II, G. C., \& Kumar, A. (2006). Interactivity and its facets revisited: Theory and empirical test. Journal of Advertising, 35(4), 35-52.

Komiak, S. Y. X., \& Benbasat, I. (2006). The effects of personalization and familiarity on trust and adoption of recommendation agents. MIS Quarterly, 30(4), 941-960.

Lee, Y., \& Kwon, O. (2011). Intimacy, familiarity and continuance intention: An extended expectation-confirmation model in web-based services. Electronic Commerce Research and Applications, 10(3), 342-357.

Liu, Y., \& Shrum, L. J. (2002). What is interactivity and is it always such a good thing? Implications of definition, person, and situation for the influence of interactivity on advertising effectiveness. Journal of Advertising, 31(4), 53-64.

Ntantogian, C., Apostolopoulos, D., Marinakis, G., \& Xenakis, C. (2014). Evaluating the privacy of Android mobile applications under forensic analysis. Computers \& Security, 42(1), 66-76.

Nunnally, J. C. (1978). Psychometric theory (2 ${ }^{\text {nd }}$ Ed.). New York, NY: McGraw-Hill.

Okazaki, S., \& Mendez, F. (2013). Perceived ubiquity in mobile services. Journal of Interactive Marketing, 27(2), 98-111.

Ou, C. X., Pavlou, P. A., \& Davison, R. M. (2014). Swift Guanxi in online marketplaces: The role of computermediated communication technologies. MIS Quarterly, 38(1), 209-230.

Park, N., Jin, B., \& Annie Jin, S. A. (2011). Effects of self-disclosure on relational intimacy in Facebook. Computers in Human Behavior, 27(5), 1974-1983.

Song, J., Kim, J., Jones, D. R., Baker, J., \& Chin, W. W. (2014). Application discoverability and user satisfaction in mobile application stores: An environmental psychology perspective. Decision Support Systems, 59(1), 3751.

Sternberg, R. J. (1986). A triangular theory of love. Psychological Review, 93(2), 119-135.

Teo, H. H., Oh, L. B., Liu, C., \& Wei, K. K. (2003). An empirical study of the effects of interactivity on web user attitude. International Journal of Human Computer Studies, 58(3), 281-305.

Tu, C. H., \& McIsaac, M. (2002). The relationship of social presence and interaction in online classes. The American Journal of Distance Education, 16(3), 131-150.

Tung, F. W., \& Deng, Y. S. (2007). Increasing social presence of social actors in e-learning environments: Effects of dynamic and static emoticons on children. Displays, 28(4), 174-180.

Taiwan Network Information Center (TWNIC), 2015/12, Survey for wireless network use in Taiwan. http://www.twnic.net.tw. 
van Noort, G., Voorveld, H. A. M., \& van Reijmersdal, E. A. (2012). Interactivity in brand web sites: Cognitive, affective, and behavioral responses explained by consumers' online flow experience. Journal of Interactive Marketing, 26(4), 223-234.

Wang, C. C., Chen, C. T., Yang, S. C., \& Farn, C. K. (2009). Pirate or buy? The moderating effect of idolatry. Journal of Business Ethics, 90(1), 81-93.

Wang, J. L., Wang, H. Z., Gaskin, J., \& Wang, L. H. (2015). The role of stress and motivation in problematic use among college students. Computers in Human Behavior, 53, 181-188.

Wimberly, T. (2012). Android market is dead, Google Play takes over starting today. Android and me, According to http://androidandme.com.

Wood, R. E., Goodman, J. S., Beckmann, N., \& Cook, A. (2008). Mediation testing in management research: A review and proposals. Organizational Research Methods, 11(2), 270-295.

Xu, C., Ryan, S., Prybutok, V., \& Wen, C. (2012). It is not for fun: An examination of social network site usage. Information \& Management, 49(5), 210-217.

Yoo, W. S., Lee, Y., \& Park, J. (2010). The role of interactivity in e-tailing: Creating value and increasing satisfaction. Journal of Retailing and Consumer Services, 17(2), 89-96.

Zeithaml, V. A., Parasuraman, A., \& Malhotra, A. (2002). Service quality delivery through web sites: A critical review of extant knowledge. Journal of the Academy of Marketing Science, 30(4), 362-375.

Zhao, L., \& Lu, Y. (2012). Enhancing perceived interactivity through network externalities: An empirical study on micro-blogging service satisfaction and continuance intention. Decision Support Systems, 53(4), 825-834.

Zhao, S. (2003). Toward a taxonomy of copresence. Presence: Teleoperators and Virtual Environments, 12(5), 445455. 